\title{
Congenital dyserythropoietic anaemia type II
}

\author{
Mohotti MGM, Gamage VNU, WeihenaEpa CD, Prasangika JPM, Guruge PKWP \\ Department of Haematology, Teaching Hospital Karapitiya, Galle, Sri Lanka.
}

Correspondence: Dr. VNU Gamage

e-mail: nuwancw84@gmail.com

\section{Introduction}

Congenital Dyserythropoietic Anaemias (CDA) are group of rare congenital anaemias characterized by ineffective erythropoiesis. CDA type II is also known by the acronym HEMPAS denoting Hereditary Erythroblastic Multinuclearity with Positive Acidified Serum lysis test. Nearly 450 cases have been reported worldwide (1). We report a case of CDA type II in a young male.

\section{Case Report}

A 24 year-old previously well male was admitted with fatigue and faintishness associated with a febrile illness for two weeks. He was found to have pancytopenia and was managed symptomatically. Two months later he presented with fatigue and yellowish sclera for one week duration. He is a product of non-consanguineous healthy parents with no significant family history.

On examination he was moderately pale and icteric with bilateral anterior cervical and axillary lymphadenopathy and mild hepatosplenomegaly. Rest of the physical examination was normal.

His initial full blood count revealed haemoglobin $4.5 \mathrm{~g} / \mathrm{dl}$, white cells $3,300 / \mathrm{mm}^{3}$ and platelet $100,000 / \mathrm{mm}^{3}$ showing pancytopaenia with evidence of a viral infection. In his second admission full blood count revealed haemoglobin $8.7 \mathrm{~g} / \mathrm{dl}$, white cells $5,800 / \mathrm{mm}^{3}$, platelet $219,000 / \mathrm{mm}^{3}$ and blood picture appeared to have normochromic normocytic red cells with increased polychromatic cells, moderate anisopoikilocytosis and irregularly contracted cells, normal white cells and platelet. Reticulocyte count was $1.4 \%$ and reticulocyte index was $1.01 \%$. Serum bilirubin was $184 \mu \mathrm{mol} / \mathrm{L}$, Direct Coombs test was negative.
Bone marrow examination revealed marked hypercellularity with massive erythroid hyperplasia showing predominantly dyserythropoietic maturation including binucleated late erythroblasts comprising $25 \%$ of the late erythroblasts and a few multinucleated erythroblasts. Granulopoiesis and megakaryopoiesis were normal. Bone marrow iron stores were $3+$ according to 0 - 6 scale (2).

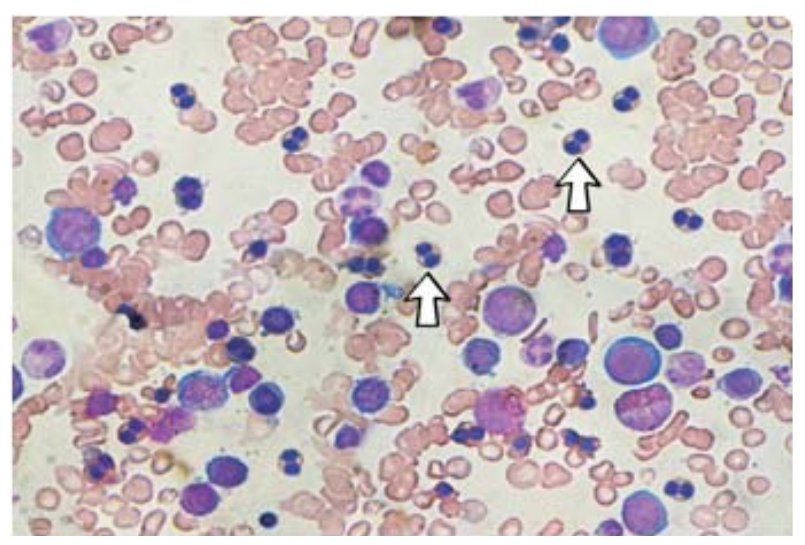

Figure: Bone marrow aspiration showing binucleated late erythroblasts (arrows)

Provisional diagnosis of CDA II was made and HAM test (3) with several donor sera was performed. It was positive showing lysis of patient's red cells with 6 out of 10 donor sera and absent lysis with his own serum.

His serum ferritin was $722 \mathrm{ng} / \mathrm{mL}$, ALT - 74U/L, AST - 89U/L, serum creatinine - $113 \mathrm{~mol} / \mathrm{L}$. Abdominal ultrasound scan revealed mild hepatomegaly, moderate splenomegaly and multiple gallbladder calculi. Skeletal survey, 2D echocardiogram and lymph node biopsy were normal. 
Based on clinical and haematological data CDA type II was diagnosed.

He was treated symptomatically and discharged on folic acid therapy after appropriate counselling. He's being followed up at our haematology clinic till date.

\section{Discussion}

CDA II is the commonest form of CDA with an autosomal recessive inheritance. The most frequently affected gene is SEC23B (CDAN2) in chromosome $20 \mathrm{p} 11.23$ leading to defective glycosylation of red cell membrane constituents (band 3, band 4.5, glycophorin, glycolipids). Abnormal band 3 proteins is hydrophobic which tends to cluster at the cell surface leading to increased binding of IgG to the red cell surface and increased phagocytosis by macrophages. Defects in glycophorin A which has complement regulating activity, make the CDA II red cells more liable to lysis in acidified heterologous sera by naturally occurring complement fixing IgM anti HEMPAS antibodies $(1,4,5)$.

It presents with anaemia of variable severity, jaundice and hepatosplenomegaly. In our patient, the diagnosis of CDA type II was made with typical bone marrow morphology and positive acid lysis with several donor sera.

Novel diagnostic tests are red cell membrane protein electrophoresis demonstrating abnormal band 3 protein and peripheral double membrane appearance in red cells on electron microscopy.

Our patient had been apparently well until his first hospital admission. He has not had any episodes of fatigue or icterus in his childhood. Even though the typical presentation of CDA II occurs during childhood, here it was delayed. His initial presentation was a transient pancytopenia which had recovered within two weeks and most probably due to a viral infection causing transient bone marrow aplasia. Since there was no significant icterus and the absence of markers of haemolysis in the initial presentation, CDA was not considered as a differential diagnosis. Yet it's extremely important to look for a congenital haemolytic anaemia in any young patient presenting with a pancytopenia. Presence of a considerable bone marrow reserve, degree of function of the reticuloendothelial system, the type of genetic mutation and absence of cardiac comorbidities are the possible factors which had affected on his delayed presentation.

Secondary haemachromatosis, cholelithiasis and paravertebral extramedullary haemopoietic pseudotumours are known late complications $(1,6)$.

Diagnosis of CDA II can easily be missed by routine full blood counts since it is a normochromic normocytic anaemia and blood picture and reticulocyte index provide important diagnostic clues of dyserythropoiesis. Therefore CDA has to be considered in the differential diagnosis of any young patient presenting with anaemia and hepatosplenomegaly.

\section{References}

1. Achille Iolascon, Maria Rosaria Esposito, Robert Russo. Clinical aspects and pathogenesis of congenital dyserythropoietic anaemia: from morphology to molecular approach. Haematologica 2012;97(12): 1786-94.

2. Barbara J. Bain D.M. Clark B.S. Wilkins. Bone Marrow Pathology, $4^{\text {th }}$ edition 2010.

3. Barbara J. Bain, Imelda Bates, Michael A. Laffan S. Mitchell Lewis. Dacie and Lewis Practical Haematology, $11^{\text {th }}$ edition, 2012.

4. Herman Heimpel, Volker Anselstetter, Ladislav Chrobak, et al. Congenital Dyserythropoietic Anaemia type II: epidemiology, clinical appearance and prognosis based on long-term observation. (American Society of Haematoloy.) Blood 2003; 102: 4576-81.

5. Sunitha N. Wickramasinghe, Bertil Glader. Congenital Dyserythropoietic Anaemias. Wintrobe's Clinical Haematology. $12^{\text {th }}$ edition. 2009.

6. Khaidem Ibochouba Singh, Jigme Tenzing Shartsho, Waikhom Ruhini Kumar Singh, et al. Congenital Dyserythropoietic Anaemia type II - a case report of two siblings in a family. Indian Journal of Haematology and Blood Transfusion 23(3-4): 116-8.

7. Sunitha N. Wickramasinghe William G. Wood. Advances in the understanding of the congenital dyserythropoietic anaemias. British Journal of Haematology 2005; 131: 431-46. 


\title{
A case of scrub typhus meningoencephalitis in Southern Province, Sri Lanka
}

\author{
Wimalarathna NTN, Weerakoon RR, Thilakasiri MCK \\ Teaching Hospital Karapitiya, Galle, Sri Lanka.
}

Correspondence: Dr. N T N Wimalarathna

e-mail: nirmani.ntnw83@gmail.com

\section{Introduction}

The incidence of rickettsial infections has increased worldwide recently. Sri Lanka also experiences a similar trend. Scrub typhus is the main rickettsioses reported in Southern province Sri Lanka (1) and it is commonly present as PUO (pyrexia of unknown origin) (2). CNS manifestations are well known complications of scrub typhus. However, due to difficulty in diagnosis at an early stage of the disease, CNS complications are often missed (3). Thus, scrub typhus complicated with meningoencephalitis has not been documented yet from Southern Sri Lanka. Therefore a case of scrub typhus complicated with meningoencephalitis is presented here. Transmission of scrub typhus requires the presence of trombiculid mites and rodents and it is caused by a gram negative intracellular pathogen orientia tsutsugamushi.

\section{Case report}

A 29 year-old previously healthy lady from Ahangama had intermittent high fever with chills, arthralgia, myalgia, headache, irritability, drowsiness and vomiting for 10 days. On admission she recorded high fever $\left(101^{\circ} \mathrm{F}\right)$. Thorough examination revealed an eschar over left breast closer to areolar (figure 1). There was marked neck rigidity. No neurological deficit was identified. Optic fundi were normal and she was haemodynamically stable.

Investigations showed a total white cell count of $10,000 / \mathrm{mm}^{3}$ with neutrophilia $(80 \%)$, normal $\mathrm{Hb}(13.2 \mathrm{~g} / \mathrm{dL})$, and marginal thrombocytopenia $\left(100,000 / \mathrm{mm}^{3}\right)$. Blood picture was bacterial in nature. Serum creatinine was $0.8 \mathrm{mg} / \mathrm{dL}$. Total bilirubin was $0.8 \mathrm{mg} / \mathrm{dL}$ and direct $0.4 \mathrm{mg} / \mathrm{dL}$, with albumin $3.5 \mathrm{gm} / \mathrm{dL}$ and total protein $6.4 \mathrm{gm} / \mathrm{dL}$. SGOT and SGPT were elevated (160 and $180 \mathrm{U} / \mathrm{L}$, respectively) and serum ALP was 90 U/L. Serum electrolytes and urine routine were normal and the imaging (chest X-ray / NCCT brain) and ECG were negative. CSF analysis on day 10 revealed lymphocytic pleocytosis ( 28 cells), high protein (85 $\mathrm{mg})$, and normal glucose $(60 \mathrm{mg} / \mathrm{dl})$. There were red blood cells $\left(240\right.$ cells $\left./ \mathrm{mm}^{3}\right)$ may be due to a collection error. Culture, gram stain and cytology of CSF were negative. Weil felix of day 12 revealed positive OX K antibody titer $(1: 320)$ while OX 19 and 2 were reported negative. Immunofluorescence Assay for IgG \& IgM was carried out at University of Peradeniaya revealed negative results for Orientia tsutsugamushi and Rickettsia conorii. Positive IgM and weekly positive IgG for Orientia tsutsugamushi were reported after an ELISA carried out at MRI Colombo.

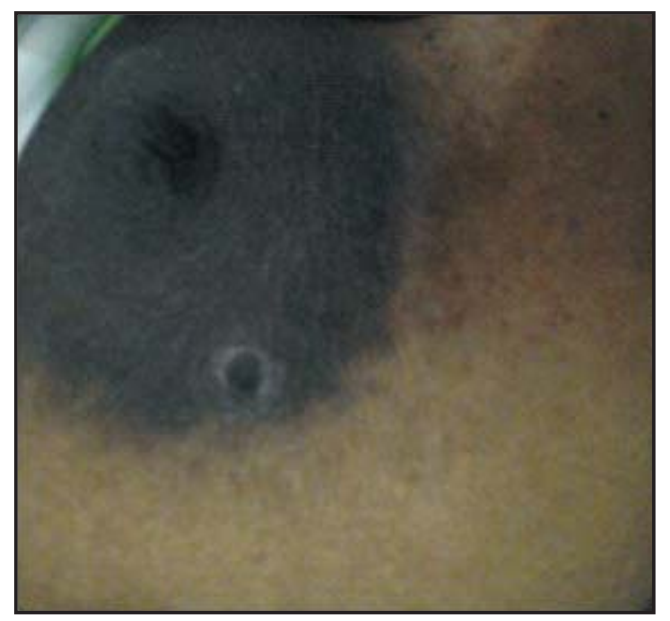

Figure : Eschar on areolar of left breast

Galle Medical Journal, Vol 21: No. 1, March 2016 
Figure 2 summarizes the drug therapy and disease repose to it. Doxycycline $100 \mathrm{mg}$ bd was started on admission but omitted as there was no improvement in 48 hours and IV chloramphenicol was started on day 12 of illness. Fever settled within 48 hours after starting IV chloramphenicol and complete, uneventful recovery was seen by 14 days of IV antibiotics.
Patient was followed up at 2 weeks, 1 month intervals after discharge. On each clinical assessment no complications were identified.

Based on the clinical picture of meningitis with eschar, dramatic response to chloramphenicol treatment, positive Weil Felix test, ELISA and CSF report, a final diagnosis of scrub typhus meningoencephalitis was made.

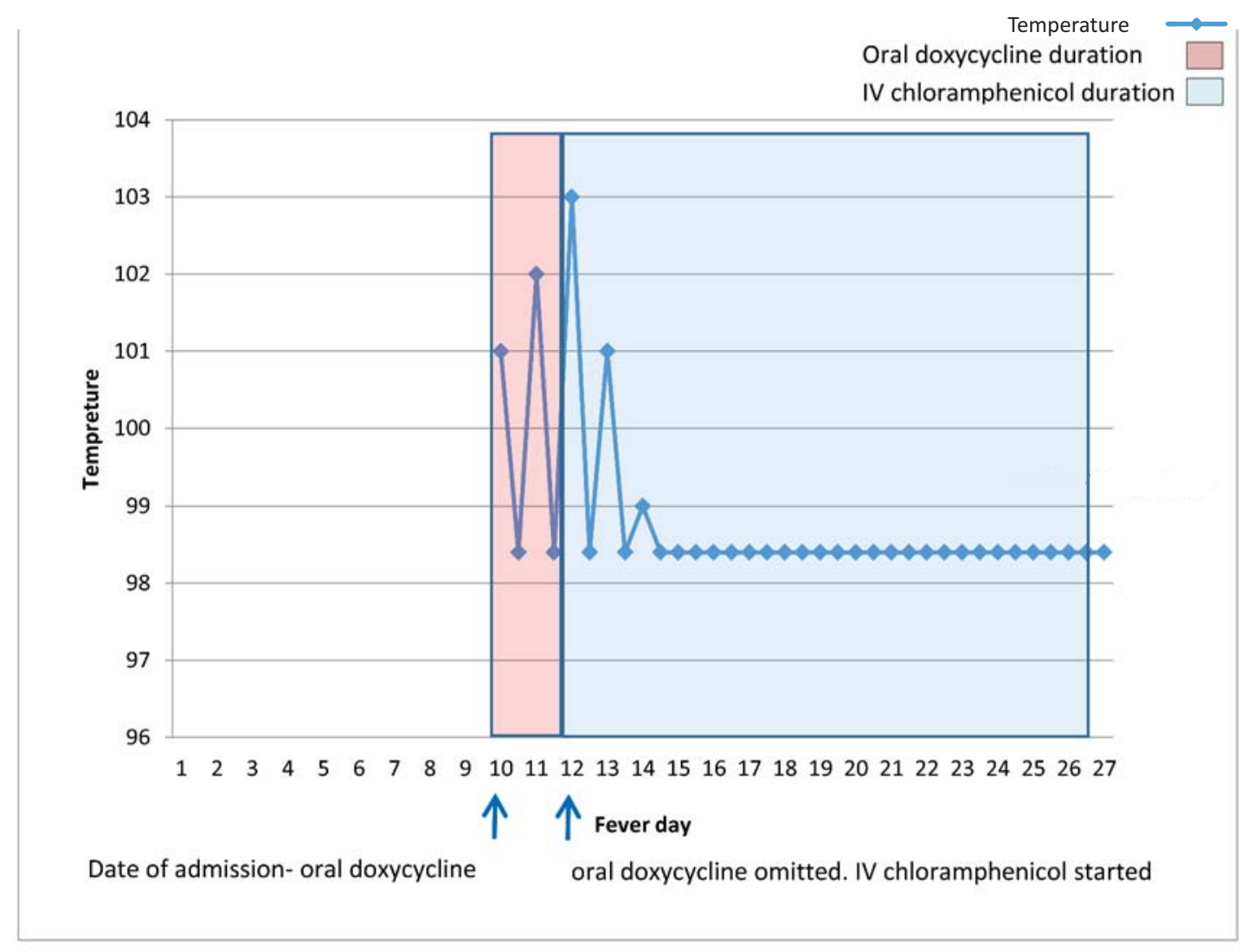

Figure 2: Temperature chart with antibiotics given on each day

\section{Discussion}

Recently a case series reported by Kularathne et al., described 17 cases of neurological manifestations of spotted fever group Rickettsiosis in Central Province, Sri Lanka (2). Premarathne et al., reported a case of hearing loss and a case with Parkinson disease due to scrub typhus in Western Province, Sri Lanka, $(4,5)$. However, this is the first documented scrub typhus meningoencephalitis case from Southern Province of Sri Lanka. It may be due to inadequate reporting, misdiagnosis, non-specific nature of the disease or due to common use of antibiotics such as doxycycline or azithromycin by physicians to treat acute febrile illnesses empirically at early stage, preventing such late complications.

The greatest degree of CNS involvement in rickettsiosis occurs in spotted fever and epidemic typhus, followed by scrub typhus (5). Although the clinical picture in this case was limited to meningoencephalitis, CNS manifestations can range from headache, seizures, delirium, hearing loss, focal CNS damage, cerebral hemorrhage, Parkinsonism and Guillain-barré Syndrome (4). 
The pathognomonic eschar is present in nearly $60 \%$ of patients with scrub typhus. It's the most useful diagnostic clue in patients with acute febrile illness in areas endemic for scrub typhus and therefore should be thoroughly examined for its often inconspicuous presence in unexposed areas of the body (5).

IFA (indirect florescent anti-body assay) is considered the gold standard. Yet it is neither the most specific nor the most sensitive diagnostic test available. The most sensitive and specific diagnostic test is in vitro isolation in cell culture, which is not available in Sri Lanka. The Weil-Felix test is commercially available. $1: 80$ titer or a fourfold rise over previous levels is significant. Weil-Felix test OXK has a specificity of $97 \%$ but less sensitive. ELISA test has more sensitivity and specificity than IFA. In this case Weil-Felix and ELISA IgM showed positive results for scrub typhus. In scrub typhus meningitis, RBC are often found in the CSF and cellular reaction is usually lymphocytic predominant with approximately $20 / \mathrm{mm}^{3}$, CSF protein is usually about $60 \mathrm{mg} / \mathrm{L}$, and glucose concentration is normal (3). In this case the cell counts, protein and sugar were compatible with CSF reports available in literature of scrub typhus meningitis.

Oral doxycycline $200 \mathrm{mg}$ oral daily for 7 days is the treatment of choice. Chloramphenicol 500mg 6 hourly and rifampicin, $900 \mathrm{mg}$ per day for a week, are alternative $2^{\text {nd }}$ line treatment. Rapid defervescence after antibiotics is so characteristic that it is used as a diagnostic test for scrub typhus (5). In this case IV chloramphenicol 500mg 6 hourly was used as its CSF penetration is superior to that of doxycycline (5).

In conclusion, we describe the first reported case of scrub typhus meningoencephalitis from Southern Province, Sri Lanka. The recent increase in scrub typhus causes a proportionate increase in the neurological complications. In order to allow early diagnosis and treatment in suspected cases and reduce morbidity and mortality, a high degree of clinical suspicion and familiarity with various clinical manifestations is vital. Therefore, we hope this report will encourage physicians to promptly diagnose, treat and further research on typhus meningoencephalitis.

\section{References}

1. Liyanapathirana VC, Thevanesam V. Seroepidemiology of rickettsioses in Sri Lanka: A patient based study. BMC Infect Dis [Internet]. BioMed Central Ltd; 2011; 11(1): 328. Available from: http://www.pubmedcentral.nih.gov/ articlerender.fcgi?artid $=3248378 \&$ tool $=$ pmcentrez\&render type $=$ abstract.

2. Kularatne SAM, Weerakoon KGAD, Rajapakse RPVJ, Madagedara SC, Nanayakkara D, Premaratna R. A case series of spotted fever rickettsiosis with neurological manifestations in Sri Lanka. Int J Infect Dis [Internet]. International Society for Infectious Diseases; 2012; 16(7): e514-7. Available from: http://dx.doi.org/10.1016/ j.ijid.2012.02.016

3. Kumar Meena J, Khandelwal S, Gupta P. Scrub typhus meningitis: An emerging infectious threat. IOSR J Dent Med Sci Ver II [Internet]. 2015; 14(10): 2279-861. Available from: www.iosrjournals.org

4. Premaratna R, Wijayalath SHNC, Miththinda JKND, Bandara NKBKRGW, de Silva HJ. Scrub typhus mimicking Parkinson's disease. BMC Res Notes [Internet]. Bio Med Central; 2015; 8(1): 438. Available from: http://www.biomedcentral.com/1756-0500/8/438.

5. Premaratna R, Chandrasena TGAN, Dassayake AS, Loftis AD, Dasch GA, de Silva HJ. Acute hearing loss due to scrub typhus: a forgotten complication of a reemerging disease. Clin Infect Dis [Internet]. 2006; 42(1): e6-8. Available from: http://www.ncbi.nlm.nih.gov/pubmed/1632308. 